\title{
Evolution of Surgery
}

\section{Rahman $\mathbf{M}^{*}$ \\ Department of Vascular Surgery, Bangladesh}

*Corresponding author: Dr. Mahbubur Rahman, Professor \& Chairman, Department o Vascular Surgery, Bangabandhu Sheikh Mujib Medical University, Shahbag, Dhaka, Bangladesh, Tel :01711529124; Email: profmahbub@yahoo.com

\section{Editorial}

Volume 2 Issue 4

Received Date: October 15, 2018

Published Date: October 25, 2018

\section{Editorial}

Surgery was initially begun by treating wounds and was largely superficial. It is hardly surprisingly that surgery of a parts of the lumen body had its origin in the treatment of wounds for in many respects man's environment is a hostile one treating him on all sides and results to the body that ill adapted to resist force.

The first surgical renaissance occurred about fifth century B.C. When the school of Hippocrates (160-377) B.C the state of the healing art to a position of scientific medicine bought [1]. The second surgical renaissance coincides with that is generally known throughout the world as the renaissance in fifteenth century Europe following the dark ages. The last half of the nineteenth century was really the third renaissance with the discovery of ether in 1842 and chloroform in 1847. At the same time the discovery, Pasteur and lister with antisepsis and asepsis showed the way of modern surgery [2]. Above all the great advances in surgery occurred since world war-2. In fact, fourth renaissance and coincides with the change of civilization with that has taken place during this period of time. Till today surgery is progressing tremendously with the innovation of new techniques and skill. The relentless efforts of surgeons throughout the world, it contributing for the development of surgery. Surgeons are now sharing their techniques and skills with fellow colleagues throughout the universe. Newer techniques are coming and being circulated in all corners. So, it is necessary to share personal experiences and knowledge for further development of surgery.

\section{References}

1. Cale WH (1960) Potentialities of surgery. Presidential address. Ann Surgery 152(3): 343-353.

2. Meade RH (1968) an introduction to the history of General Surgery. Philadelphia, Saunders.

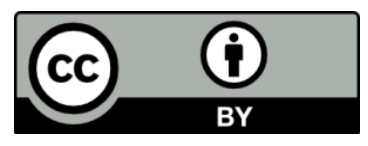

